\title{
Discussion on the Teaching Reform of Massive Open Online Courses in Universities
}

\author{
Ying Li \\ School of Economics \\ Tianjin University of Commerce \\ Tianjin, China
}

\begin{abstract}
As a new education mode, the massive open online course (MOOC) has received attentions of college teachers. It is the inevitable direction of the teaching mode reform in the internet era and the big data era. In the recent two years, our country has issued many documents, which pay attention to the construction of online class teaching and encourage universities to conduct it. It has become a sally port to improve the teaching quality of universities. However, many problems exist in the process of construction because the online class teaching of universities in our country has a late start at the same time the research and the practice are at the exploratory stage. Therefore, through practical investigation, this paper reveals the development status of online class in our country in detail, seizing the current main problems and exploring the main reasons for its existence. Meanwhile, the corresponding opinions and suggestions are proposed to promote the teaching reform of MOOC in universities according to the investigation result.
\end{abstract}

Keywords-massive open online course; teaching reform; online learning

\section{INTRODUCTION}

The massive open online course is "MOOC" for short. Originated from 2008, it was proposed by Dave Cormier and Bryan Alexander, two scholars from the University of Price Edward Island in Canada jointly. In the same year, Downs and Simons jointly established the world's first MOOC, bringing the popularity to construct "MOOC" worldwide. People have paid an increasing attention to it. In 2001, the MOOC of Artificial Intelligence provided by Professor Sebastian Thrun in Stanford University attracted more than 160,000 students from over 190 countries to register. Students begin to acknowledge and accept the model of teaching. In 2012, three MOOC platforms namely Edx, Coursera and Udacity were constructed worldwide, making the construction of MOOC on the right track increasingly. Nowadays, MOOC has become the necessity of the course reform in universities in the "Internet plus" and big data era. In China, many universities also begin to explore the reform of the MOOC. Top colleges and universities at home such as Tsinghua University also participate in the world's construction system of MOOC. It is foreseeable that the construction of "MOOC" will become the emphasis of the teaching reform in universities in the new era,

Fund project: Research project of the education system in Tianjin City in 2016 "Research on Promoting the Teaching Reform of Massive Open Online Course in Universities". assuming the heavy task of improving the teaching quality of universities.

\section{THE CURRENT SitUATION OF “MOOC” CONSTRUCTION IN CHINA}

MOOC is the Massive Open Online Course based on the internet technology. The course is neither the traditional television teaching nor the network video class. Similar to the online college education, it refers to the teaching model that takes the network video as the teaching means and makes use of the forms like online teaching, homework correction, interaction with the students and evaluation as well as certification under the unified management of the corresponding team. The teaching scale of MOOC is large. The number of people who study online on a course reaches up to tens of thousands. It makes more people enjoy the resources of higher education; MOOC depends on the network and enables people to dominate their learning time freely at the same time improving people's interest in the independent learning; MOOC has a high requirement for teachers, requiring teachers to clearly teach the course within a short period of time and promoting teachers to ceaselessly improve the teaching contents and teaching methods; MOOC takes advantage of the big data analysis and couples back the homework and learning condition of students, urging teachers to improve the teaching and then the teaching quality. MOOC is the necessity of the reform of teaching model in the internet era and has received attention from the educational world because it has adjusted to the requirement of the informationbased development.

The construction of online courses in our country has begun prior to the appearance of MOOC, laying a solid foundation for the construction of MOOC. In 2000, the Ministry of Education in our country advocated the universities to conduct the construction project of "new century network course". In 2003, the Ministry of Education advocated the construction project of "Classical Course at National Level and City Level". In 2012, the three MOOC platforms of Edx, Coursera and Udacity were constructed at abroad. Universities in China also participate in it afterwards. Top universities in China such as Tsinghua University, Peking University and Fudan University take the lead to join in the platforms of Edx and Coursera. Afterwards, other universities also begin the research and development and construction of 
MOOC. So far, Tsinghua University independently establishes "Xuetang X" and Shanghai Jiaotong University independently constructs "CNMOOC". Shenzhen University takes the lead to construct "UOOC Alliance". East China Normal University constructs "MOOCs Alliance C20". The construction of MOOC can't do without the support of enterprises. In foreign countries, enterprises develop the platform and construct it with schools jointly. Our country is in the same way. The most influential is the platform of "China University MOOC" launched by Netease Cloud Class and iCourse jointly. Currently, more than one hundred universities have opened the MOOC on the platform. According to the related data statistics, over 700,000 people have registered on the iCourse to learn independently. Of course, it not only includes the university MOOC but also includes MOOC of vocational education, but most of the students gather in the university MOOC.

Although only having a history of two years, MOOC has an amazing development speed. The investigation result shows more than $90 \%$ of students know of MOOC through the introduction of other students mainly. A total of $65.7 \%$ of students investigated have experienced MOOC. At the same time, $26.8 \%$ of students are learning by way of MOOC. Although the number of people using MOOC to learn is not large, most of the students have known of and experienced it after two years since the appearance of MOOC. Furthermore, some students are using it, showing MOOC has received a lot of attention.

MOOC enables more students to enjoy the educational resources of higher quality. The resources of "China University MOOC" in the "iCourse network" show nowadays, the MOOC in China has involved humanities, social science, literature, art, engineering, computer, economics, business, mathematics and foreign languages, almost covering all the disciplines. The teachers range from professors to ordinary lecturers, who are the backbones of teaching in universities. The teacher of each course has the unique teaching style. Particularly, we can learn the courses of famous teachers of national level, provincial and municipal level. The sharing of the high quality educational resources can't be realized in the past.

\section{The CURRENT Problems IN THE CONSTRUCTION OF "MOOC" IN CHINA}

Many people have questioned the MOOC when it is booming. In 2014, the survey data issued by Sloan Consortium (university research institute) in America show, the $65.8 \%$ of directors of universities worry about the future of MOOC. In the investigation, a total of $42.3 \%$ of people hold a negative attitude to the future of MOOC in China, which is beyond our expectation. Therefore, we can infer problems exist in the MOOC in China and its development faces many challenges.

\section{A. The Construction Fund Is Insufficient}

The construction, maintenance and update of MOOC require large quantities of funds. In foreign countries, the initial capitals for the construction of the three platforms of edx, Udacity and Coursera at abroad are 60 million USD, 22 million USD and 16 million USD respectively. An enormous sum of money is invested for the construction, development and update of MOOC at the later period. In our country, Tsinghua University and Fudan University also invest tremendous capitals in developing the MOOC platform. The capitals mainly come from "the comprehensive investment in the 12th Five-year Plan" and the fund for discipline construction. However, the funds are much less than that of the foreign countries. The investigation shows most of schools in our country construct MOOC through the independent contribution of capital. The majority of money comes from the construction fund allocated by the government. Few schools construct together with enterprises, leading to the limited source of construction funds.

The insufficient construction fund is adverse to the hardware construction such as the expansion of the network capacity, the increase of network speed and the construction of new platforms, and the software construction of employing more teachers, administrators of the platform and invigilators. According to the investigation result, $92.5 \%$ of teachers observe the funds of constructing MOOC of the school come from the funds of comprehensive investment and the funds for discipline construction, but the funds are limited. The payment for teachers who provide courses is little, so they lack the enthusiasm in constructing MOOC. The insufficient construction funds prevent more high quality educational resources from becoming MOOC, as well as the MOOC from being provided on a higher platform.

\section{B. Teachers Lack Enthusiasm for the Construction}

MOOC enables more teachers to express themselves before students, so that teachers can gain acceptance of more students and colleagues. Particularly, in each MOOC, the teacher must summarize the contents of a chapter concisely and comprehensively within 10 to 15 minutes and teach it to students through being both excellent in voice and affection. The varied levels of students require teachers to better grasp the teaching process in class. Actually, the construction of MOOC provides teachers with a good platform for continuously improving themselves, availing the growth of teachers. It is a way for teachers become renowned. However, the investigation result shows only $67.2 \%$ of teachers have seen MOOC videos, only $18.9 \%$ of teachers have participated in the construction of MOOC, and only $52 \%$ of teachers video MOOC. Obviously, teachers lack enthusiasm for the construction of MOOC. It is because the promotion of teachers is closely linked to the level of scientific research. Teachers concentrate upon writing papers and working on projects, paying inadequate attention to teaching. The construction of MOOC requires teachers to devote more energy into it and prepare for lessons. However, teachers cannot do that under the current promotion system. Besides, at present, the limited construction fund makes teachers who participate in the construction of MOOC cannot get the corresponding payment. In most cases, the school leaders assign the task of course construction or the classical courses require MOOC. Teachers construct MOOC with the aim of fulfilling tasks, leading to the low enthusiasm. At the same time, the quality of courses cannot be guaranteed. 


\section{The Drop-out Rate of Students Stays at A High Level}

As a new type of teaching model, MOOC has received more and more attentions from students. Tens of thousands of students have registered and learned some courses. However, the investigation result shows probably $68.1 \%$ of students cannot hold on straight to the end of a course. That's to say, the drop-out rate of students is very high. The reason is that people universally reflect MOOC is a pattern of independent learning. Students select courses according to their interests and needs. However, because the MOOC lacks supervision, especially the personal supervision of teachers in class and the learning time is flexible; students think they can learn the course tomorrow since they fail to learn it today. Therefore, they are unable to keep pace with the course because they have left more and more courses. Namely, the unsound corresponding restriction mechanism leads to the relatively poor consciousness of them. Students lack interests in learning and give up halfway. What's more, the tuition will not be collected for the majority of MOOC in China. Only low fees are collected in the examination and manufacturing certificates. Unlike the ordinary universities, MOOC does not evaluate the pass of courses through the attendance performance and the final exam result, failing to supervise students effectively. Many students learn MOOC not for a certificate because the degree of social recognition of the certificates is not high. Most of students base on personal interests and needs. Depending on interests and without supervision, students will have a poor learning persistence and easily drop out.

\section{The Teaching System of MOOC Is Unsound}

As a new type of teaching model, MOOC is still at the exploratory stage in China. Although many universities have provided MOOC involving such disciplines as economy, management, engineering and art, on the whole, the MOOC platform only provides fragmented courses instead of forming a learning system. According to the survey result, students universally reflect the MOOC is fragmented and the explanation of the corresponding disciplines is relatively shallow. For example, after learning the course of Junior Western Economics, they have difficulties in finding the corresponding courses to learn Medium Western Economics and Senior Western Economics. Although the population difference of MOOC is strong, most of the courses are introductions or elementary courses, making students have the feeling of "only see the trees instead of the forest", which is adverse to the persistence of learning.

MOOC is an online learning model in a sense. Although most of MOOCs also provide such platforms as BBS for teachers and students to communicate, in most cases, it cannot realize the timely communication between students and teachers. The survey results show students think MOOC resembles online courses or video courses. They fail to receive the careful guidance of teachers when they have something confused. It's difficult to realize the one-to-one guidance. Therefore, the current MOOC is similar to the video courses, lacking the individualized guidance on students. Besides, the feedback of students to teachers is limited. Without communication and the sufficient information of students for course learning, teachers neither improve courses pertinently nor improve themselves.

The evaluation system of MOOC is doubted by people. Related people have opinions on the problem of whether the certificate shall be issued for MOOC. MOOC is not the real university. Its certificate cannot be accepted by the educational management departments. The starting point of the MOOC construction is to let more people enjoy more educational resources, advocating the independent learning, in order to improve the cultural quality of all the people. However, in the investigation, many students address the certificates are the stepping-stone to success and hope the certificates of MOOC can be accepted by relevant departments. In this way, the learning interests and consciousness will be improved greatly.

\section{E. The Function of Improving the Teaching Quality of Universities Is Limited}

The appearance of MOOC is the necessity of the teaching reform in universities in the internet era. In some sense, it is an auxiliary form of classroom teaching for college students, as well as the platform for college students to listen to the excellent courses at national level or provincial level or ministerial level and world level. However, the survey result shows at present, the proportion of college students who choose MOOC is only $52.3 \%$, much less than the number we expect. Other students who do not receive the higher education pay more attention to MOOC. Therefore, at present, MOOC does not become the auxiliary means of college education, and its function of improving the teaching quality of universities is limited.

The construction of MOOC is full of changes for college teachers. Most of the college teachers clearly show they are under great pressure to prepare and video MOOC. It is full of challenge to explain the related knowledge points through excellent voice and affection within the short period of 15 minutes. Therefore, many teachers, especially some experienced teachers are not willing to make efforts to construct it. Young teachers are not experienced or famous, so their MOOC cannot receive a high attention. Particularly, most of teachers who have participated in the construction of MOOC express although they gain in the process of constructing MOOC and it indeed promotes the diversification of the organizational form of classroom teaching, the persistence of MOOC construction is always poor, failing to greatly change the current situation of teaching in universities.

\section{Countermeasures to Promote the TEACHING REFORM OF "MOOC"}

\section{A. Strengthen the Coalition of College and Enterprise and Increase the Input of Construction Funds for MOOC}

Whether the construction fund is sufficient plays a key role in the construction of MOOC and the update and maintenance in the later period. Therefore, at present, we must focus on solving the problem of insufficient construction fund. The investment of the government in MOOC is the main source of the construction fund of MOOC in our country. The government shall continue to vigorously support the 
construction of MOOC. At the meantime, according to the experience of constructing MOOC at abroad, most of them are the form of coalition of college and enterprise. We also need to refer to the model. The construction funds in schools are limited. Enterprises not only have adequate funds but also have technicians related to the development, construction and maintenance of the computer network, the big data processing and advertising. The enterprises are responsible for the development and construction of the platform, and teachers in schools take charge of the lectures on the professional knowledge. The cooperation of the two can solve the problem of funds. Most importantly, they can exploit the advantages to the full respectively. The effects and efficiency of MOOC videoed are better and higher. It can meet the needs of students better, at the same time, making the enterprises have a better income.

Enterprises must assume sole responsibility for its profits or losses. They see the business opportunity in choosing to cooperate with schools. As the developer of platforms, enterprises have the main source of income of the platform. Therefore, in our country, the charges shall be collected for some MOOCs, and then it shall be divided for schools and enterprises according to a certain ratio. Besides, the fee of invigilation service, the fee of cooperating with the publishers, the fee of cooperating with head-hunting companies, the academic advertising expenses as well as the counseling fee of students will become the source of income of enterprises. Enterprises will better cooperate with schools only after they see the broad market, so as to relieve the difficulty of insufficient construction funds.

\section{B. Further Improve the Evaluation System of Teachers and Stimulate Their Enthusiasm in Participating in the Construction of MOOC}

At present, the evaluation system of college teachers pays far more attentions to the scientific research instead of teaching. Therefore, teachers attach importance to the scientific research and neglect teaching, being indifferent to the reform of teaching way and lacking enthusiasm in constructing MOOC. The construction of MOOC indeed can bring a certain surplus income for teachers. However, teachers pay more attention to the personal position promotion than the income. Meanwhile, the current evaluation system pays no attention to teaching. Therefore, essentially, the current evaluation system of teachers must be changed and more attentions shall be paid to teaching, in order to stimulate the enthusiasm of teachers. The evaluation system shall embody the completion of teaching workload. The quantitative evaluation of teaching quality is more important, such as the feedback of students, the appraisal of famous teachers and the provision of video open courses. Of course, the provision and maintenance of MOOC can be taken as an index in the evaluation system. The results of related competitions on the MOOC at the national level or video open courses can be included in the evaluation index. In this way, it can improve the enthusiasm of teachers in constructing MOOC and teaching reform and then promote the improvement of the teaching quality.

\section{Standardize the Supervision Mechanism of MOOC and Improve the Ability of Students in Independent Learning}

MOOC is not the real teaching in colleges, having a world of difference from the colleges. In colleges, the performance of students in attendance and homework at ordinary times is included in the result of the final exam. Students can obtain the graduation certificate and the certificate of degree after all the results are qualified and they get all credits. The supervision on students is perfect. However, because MOOC mainly adopts the online education and the existence of evaluation depends on students freely, the approval degree of the certificate of MOOC is not high. Therefore, the degree of restricting students is not high. Many students only learn it by virtue of interests and few can complete the whole course.

Tremendous human and material resources are invested in the construction of MOOC, in order to let more people receive the educational resources of higher quality and improve the cultural quality of the whole nation. Since it aims at making the students who fail to receive the higher education receive it, it shall be supervised strictly like universities to greatly improve the teaching effects. Because the quality of students of MOOC is uneven and the learning objectives of students are not unified like colleges, the supervision is very difficult. For the sustainable development of MOOC, the sound supervision mechanism and the strict work attendance checking system shall be established and the invigilation management shall be strict, in order to improve the quality and the social approval degree of the certificates issued. Measures to punish students who are absent from too many courses must be taken, make those who have used MOOC feel like truly receiving the higher education.

\section{Improve the Teaching System and the Teaching Quality of MOOC}

At present, the main reason why many students do not choose MOOC is because MOOC does not have a complete teaching system. Students feel they cannot learn the related professional knowledge systematically. Universally, they can learn the junior knowledge easily, but have difficulties in learning it further. The same knowledge point has the MOOCs of different teachers. The selection of MOOC is also very difficult. There is little information about the introduction to the course before class, the target students and the evaluation of other students, which are not enough to serve as the reference index. Most importantly, the courses are not systematic.

The establishment and improvement of the teaching system of MOOC requires the input of more manpower and material resources. We shall refer to the teaching system of ordinary colleges but cannot copy mechanically. The corresponding teaching system must be established and the more practical requirements must be valued according to the characteristics of subjects in MOOC. The system of MOOC in the future shall be increasingly close to the teaching system of college education. The practicability is the most important. Of course, we have to absorb the experience at abroad in setting the course system and focus on the internationalization. The provision of MOOC system aims at letting students receive the international advanced education via remaining within doors. 
Of course, even the most suitable education system requires teachers of a higher level to teach courses. Therefore, the selection of teachers is also of vital importance. The teachers suitable for students shall be chosen. More students are attracted to attach importance to MOOC education through the charm of teachers in teaching, in order to enhance the effect of independent learning and the teaching quality.

\section{E. The Function of MOOC Must Be Exerted to Substantially Improve the Teaching Quality of Universities}

At present, the higher education in China is monopolistic. It's very difficult for students to receive more education once they start school. The appearance of MOOC covers the shortage. We can receive the teaching of renowned teachers at home and abroad at short range through learning MOOC. MOCC and university teaching just become the competitors of college education, so it avails the improvement of teaching quality in universities.

The construction of MOOC makes more teachers pay attention to the teaching reform. Participating in the construction of MOOC makes teachers improve the teaching quality. Particularly, some teachers can make the best of the both worlds through observing the MOOC of other teachers, making up for the deficiencies in learning. They can explore the teaching methods more suitable for students through the scientific research of MOOC. It fully stimulates the enthusiasm of teachers in the fierce competition, improving the teaching quality of universities faster.

\section{CONCLUSION}

MOOC is important means to achieve diversified teaching, but also an important way of teaching reform. Nowadays, the informatization and big data become the theme of the times. The colleges and universities need to popularize MOOC and improve the teaching quality of MOOC. At present, MOOC lack the construction funds. The teachers' enthusiasm isn't high, and the drop-out rate is high. The teaching system isn't perfect. MOOC has limited significance to the improvement of teaching quality. In view of the main problems, it should mainly increase the cooperation between school and enterprise, improve the teacher evaluation mechanism, standardize supervision of MOOC, improve the teaching system and give full play to the role of MOOC. In teaching practice, it should constantly improve the construction of MOOC system. Then, more students would enjoy the teaching results of MOOC.

\section{REFERENCES}

[1] Chen Ye. The "Eight-year Itch" of the Teaching of "MOOC" [J], University Education, 2016(9): 60-62

[2] Han Xibin, Cheng Lulan, Cheng Jiangang. Analysis and Design of the Perspective of Pedagogy of MOOCs [J], E-education Research, 2014(1): 45-51

[3] Sir John Daniel, Ding Xingfu (translator). The Development Prospect of the Massive Open Online Courses--Further Consideration on the Confusion Caused by the Related Myth, Paradox and Possibility [J], Open Education Research, 2013(6): 42-55

[4] Li Lin. Thinking on the Development of the Massive Open Online Courses [J], Education Exploration, 2014(8): 35-36
[5] Wang Wenli. The Influence of the Development of MOOC on the Higher Education [J], Jiangsu Higher Education, 2013(2): 53-55

[6] Yuan Li, Stephen Powell, Bill Oliver, Post MOOC Era: The Sustainable Development of the Online Education in Universities [J]. Ope Education Research, 2014(6):44-52

[7] Zhang Qian. Analysis on the "Open Type" Innovation and Entrepreneurship Education Mode Based on MOOC [J], Continue Education Research, 2016(10): 31-33 